\title{
Anti diabetic activity of the stem bark extract and fractions of Faidherbia albida Del._(Mimosaceae) in murine model.
}

\author{
A.J.Kashimawo ${ }^{1,2 *}$, J.A. Kolawole ${ }^{2}$, J.O. Kemelayefa ${ }^{3}$ \\ ${ }^{I}$ Department of Pharmaceutical and Medicinal Chemistry, Niger Delta University, Wilberforce Island, Bayelsa \\ State, Nigeria. \\ ${ }^{2}$ Department of Pharmaceutical Chemistry, University of Jos, Jos, Nigeria \\ ${ }^{3}$ Department of Pharmacology and Pharmacotherapeutics, Niger Delta University, Wilberforce Island,Bayelsa \\ State, Nigeria. \\ Corresponding Author: A.J.Kashimawo
}

\begin{abstract}
Background: In our continued search for potent anti-diabetic compound(s) from plants and natural sources, we tested crude extract and fractions of the stem bark of Faidherbia albida - a plant traditional used in the management of diabetes mellitus in Northern Nigeria, on alloxan induced diabetic rats to obtain the most active fraction.

Space and Duration of Study: The study was conducted between November 2016-March 2017 using laboratories of Departments of Pharmaceutical Chemistry and Department of Pharmacology of Niger Delta University, Wilberforce Island, Amassoma, Bayelsa State, Nigeria.

Methodology: Twenty five rats weighing between 150-200g were made diabetic with alloxan injected peritonialy. They were divided into five groups of five rats each. A sixth group of five normal fats were used for the study. They were treated with F.albida crude extract and fractions as follows; Group 1-crude extract $200 \mathrm{mg} / \mathrm{kg}$, Group 2- ethylacetate fraction $50 \mathrm{mg} / \mathrm{kg}$, Group 3- Butanol fraction $50 \mathrm{mg} / \mathrm{kg}$, Group 4Glibenclamide 5mg/ kg, Group 5- untreated diabetic rats, Group 6- Normal rats. Treatment continued for 28 days with blood glucose and weight check weekly. Animals were sacrificed and blood samples collected for biochemical parameters.

Results: The blood glucose level of the group treated with ethylacetate was lowered to $142 \mathrm{mg} / \mathrm{dl}$ which compares favourably with the group treated with glibenclamide $(112 \mathrm{mg} / \mathrm{dl})$ as opposed to the diabetic untreated group $(380 \mathrm{mg} / \mathrm{dl})$ at the end of four weeks of treatment. Ethylacetate fraction treated rats showed the least percentage weight loss while there is a significant weight loss $(=0.05)$ in the diabetic rats

Conclusion: Ethylacetate fraction of F.albida showed remarkable effect on blood glucose level and reduced the weight loss in diabetic rats and thus more promising to be further evaluated for bioactive substances.
\end{abstract}

Keywords: F.albida, Diabetes mellitus.

\section{Introduction}

Diabetes mellitus (DM) is a metabolic disease of hyperglycemia or chronic increase blood glucose level with disturbing influences on starch, fat and protein metabolism due to absence of or reduced insulin secretion (Velasco et al., 1993). It is a life-threatening chronic metabolic disease which currently afflicts 3\% of the world population (Abdalla et al., 2012). Over 90\% of diabetic populations are diagnosed with type 2 diabetes. The defect impairs glucose homeostasis in diabetic patients, resulting in hyperglycemia [Ruta et al 2013]. Therefore, one important method of treating patients with type 2 diabetes is to control blood glucose levels, which can be achieved by an increase of insulin release (insulin releasers) or insulin action (insulin sensitizers), a decrease of intestinal glucose uptake (enzyme inhibitors), and so forth [ref]. However, few clinical drugs are available for diabetes, and those that are available usually have adverse side effects, decreased efficacy over time and are expensive (Vishwakarma et al., 2010). Therefore, research and development of novel drugs for diabetes have been in great demand especially from natural sources especially from plants. One such plant used traditionally in managing DM is the stem bark extract of $F$. albida.

F. albida is commonly called Apple ring acacia or Gawo in Hausa language. The plant is native to Africa, Middle East and Asia particularly semi arid areas. It grows up to $30 \mathrm{~m}$ tall, leaves compound and bipinnate with leaflets borne along the pinnae. It has grey to whitish bark, smooth when young, fissured, flaky and cork-like when matured (Wood, 1992). Traditional uses include treatment of diarrhea, leprosy, pneumonia cough and ease delivery during childbirth (Orwa et al., 2009). Previous studies have shown that F. albida 
possess anti-malarial activity (Oluwakanyisola et al., 2010), antimicrobial (Usman et al., 2013), anti-pyretic, anti- inflammatory and anti-diarreal effects (Tijani et al., 2008). Acute toxicity studies show that the plant part extract is relatively safe (Salawu et al., 2010, Lawal et al., 2012). Anti-diabetic activities have been reported for various plant parts of $F$. albida such as methanolic root bark extract (Salisu et al.,2009), aqueous seed extract (Gaber et al., 2013), aqueous stem bark extract (Umar et al., 2014). The present investigation is directed to the exploration of the anti- diabetic activity of fractions of $F$. albida and justify the use $F$. albida in the management of Diabetes mellitus..

\section{Materials And Methods}

2.1 Plant collection: The stem bark of $F$. albida was collected from its trees in Bauchi, North East Nigeria in April 2014. It was identified and authenticated by Mr JJ Azila of the Federal college of Forestry, Jos, Nigeria, where a voucher specimen was deposited.

2.2 Preparation of extracts:The stem bark was shade dried for 21 days, then pulverized. $1000 \mathrm{~g}$ of the plant stem bark was macerated with $2.5 \mathrm{~L}$ of $50 \%$ ethanol for 72 hours and filtered with cotton wool, the marc further extracted twice for 48 hours each with $50 \%$ ethanol and filtered. The combined filterate was concentrated on a rotary evaporator and subsequently dried on a water bath at $50^{\circ} \mathrm{C}$. The dried extract $(82 \mathrm{~g})$ was weighed and $50 \mathrm{~g}$ was successively partitioned in a separating funnel with n-hexane, dichloromethane, ethylacetate and n-butanol. The fractions were dried and kept in a dessicator for use.

2.3 Phytochemical screening: Standard protocol for screening plant extract for the prescence of secondary metabolites were used (Trease and Evans, 1983; Odebiyi and Sofowora, 1978). The secondary metabolites tested include tannins, alkaloids, flavonoids, saponins, glycosides, phenols.

2.4 Experimental animals: Adult male albino wistar rats weighing 150-200g were obtained from the animal house of the Department of Pharmacology and used for the studies. The rats were housed in well ventilated cages and maintained under standard room temperature of $25 \pm 5^{\circ} \mathrm{C}$, relative humidity of $35-60 \%$ and 12 hours light/dark cycles. All the rats were fed with standard pellet diet and potable water given freely before the experiment.

2.5 Acute oral toxicity study: A dose of $2000 \mathrm{mg} / \mathrm{Kg}$ body weight was given. The signs of toxicity and or mortality observed for the first 3 hours and the next 48 hours. No sign of toxicity was observed, thus doses of $100-400 \mathrm{mg} / \mathrm{kg}$ body weight was selected for antidiabetic activity.

2.6 Induction of Diabetes mellitus (Alloxan model): Diabetes was induced by single intra peritoneal injection of $150 \mathrm{mg} / \mathrm{kg}$ of Alloxan dissolved in normal saline. To prevent fatal hypoglycemia, the rats were given $5 \%$ glucose within the first 24 hours. Fasting blood sugar of rhe rats were measured after 72 hours using Accu-chek glucometer (Roche Diagnostics, USA). Rats with fasting blood sugar level above 200mg/Dl were considered diabetic. All protocols were conducted under compliance of animal ethics guidelines for laboratory animal care and use of University of Jos, Nigeria.

2.7 Estimation of fasting blood glucose: Blood glucose was measured using Accu-chek blood glucose monitor. The glucose dehydrogenase present in the strip converts glucose present in the blood sample to gluconolactone and this produces electrons which creates a proportional current which is displayed on the meter. The strip is sensitive to the gluconolactone that with increasing concentration, the strip changes color from yellow through lemon to green and dark green.

2.8 Experimental design (Alloxan model): 25 wistar rats confirmed to be diabetic using Accu-chek glucometer were divided into five groups of 5 rats each, weighed individually and marked serially for differentiation. A sixth group of five normal rats was added without induction to serve as control. In group 1, diabetic rats were treated with $F$. albida crude extract $200 \mathrm{mg} / \mathrm{kg}$ body weight. In group 2 , diabetic rats were treated with ethyl acetate fraction $50 \mathrm{mg} / \mathrm{kg}$ body weight. Group 3 diabetic rats were treated with n-butanol fraction $50 \mathrm{mg} / \mathrm{kg}$ body weight. In group 4 , the diabetic rats were treated with standard drug glibenclamide $5 \mathrm{mg} / \mathrm{kg}$ body weight. Group 5 diabetic rats were given distilled water and serves as negative control while group 6 were normal non-diabetic rats were given crude extract $200 \mathrm{mg} / \mathrm{kg}$ body weight to serve as positive control.

2.9 Collection of blood samples and estimation of biochemical parameters: At the end of the experiment, day 28, the rats were fasted overnight and dissected under ether anaesthesia. The pancreas, kidney and liver were collected into heparinised tubes. Blood samples were collected and allowed to coagulate followed by centrifugation at $3000 \mathrm{r} / \mathrm{min}$. at $4^{\circ} \mathrm{C}$ to obtain serum. Sera were divided into portions in tubes and stored at $-8^{\circ} \mathrm{C}$ for biochemical analysis.

Statistical analysis: Data was expressed as means \pm SD and analysed using statistical software package (SPSS for Windows version 15, IBM Corporation, NY, USA). Values were considered significantly different at $\mathrm{p}=$ 0.05 . 


\subsection{Phytochemical screening}

\section{Results And Discussion}

Results of the phytochemical screening in Table 1 showed that Steroids, glycosides, terpenoids and flavonoids were present in the crude extract of the stem bark of $F$. albida. These secondary metabolites were reported to possess biological activities including antibacterial, antiviral, antioxidant, anti-inflammatory and analgesic activities (Usman et al., 2013). Terpenoids found in the plant may contribute to its hypoglycemic activities (Doughari .et al., 2012). Terpenes and terpenoids have been found to stimulate insulin secretion or possesses insulin like activities (Inouyea .et al., 2012) Terpenes have been reported to restore normal glycogen metabolism when hepatic glycogen concentration is reduced (Nabil . et al., 2016). Glycosides and flavonoids have been found to possess hypoglycemic properties (Brownlee and Cerami ., 1981).

Table 1. Phytochemical constituents of the stem bark extract of F.albida

\begin{tabular}{|l|l|}
\hline Compounds & F. albida crude extract \\
\hline Alkaloids & - \\
\hline Anthraquinones & - \\
\hline Steroids & + \\
\hline Saponins & - \\
\hline Flavonoids & + \\
\hline Glycosides & + \\
\hline & \\
\hline
\end{tabular}

\subsection{Effect of crude extract and fractions of . albida on body weight in normal and diabetic rats}

The result of the effect of stem bark extract and its fractions on body weight of alloxan induced diabetic rats after treatment for 4 weeks is presented in Table 2. Diabetic rats lost weight significantly $(P<0.05)$ compared to the normal control and the crude extract treated rats with non significant weight loss. The ethyl acetate fraction treated rats weight loss is similar to those of the crude extract treated rats.

The loss in body weight of diabetic rats could be due to dehydration, fat catabolism or protein breakdown (Subramania et al.,2008). Normal body weight gain indicates efficient glucose metabolism whereas in diabetes, glucose is not available in the cells thus use alternative fats and proteins for energy leading to weight loss. The extract from F.albida and its fractions reversed significantly the weight loss in the diabetic rats to varying degrees with the ethylacetate fraction treated rats showed a slight weight gain $3.2 \%$ at four weeks while the control rats showed $6.1 \%$ weight gain over the same period.

Table 2. Effect of crude extract of F.albida and fractions on body weight in normal and diabetic rats

\begin{tabular}{|l|l|l|l|l|l|l|}
\hline GRP & & & WEEK 1 & WEEK 2 & WEEK 3 & WEEK 4 \\
\hline 1 & CRUDE EXTRACT & $170.9 \pm 2.34$ & $173.1 \pm 0.77$ & $170.9 \pm 2.49$ & $172.7 \pm 1.05$ & $167.8 \pm 0.9$ \\
\hline 2 & ETOAC FRACTIO & $165.6 \pm 2.12$ & $162.9 \pm 1.02$ & $163.2 \pm 2.17$ & $167.8 \pm 2.41$ & $171.1 \pm 2.11$ \\
\hline 3 & BUTANOL FRAC & $195.5 \pm 1.66$ & $194.8 \pm 1.52$ & $193.1 \pm 1.36$ & $184 . .9 \pm 2.12$ & $176.9 \pm 2.23$ \\
\hline 4 & GLIBENCLAMIDE & $155.7 \pm 1.82$ & $143.1 \pm 1.87$ & $142.9 \pm 1.56$ & $143.8 \pm 1.66$ & $146.9 \pm 1.57$ \\
\hline 5 & DIABETIC & $198.1 \pm 2.52$ & $193.2 \pm 2.01$ & $173.4 \pm 1.93$ & $164.6 \pm 2.21$ & $154.9 \pm 1.96$ \\
\hline 6 & N CONTROL & $172.6 \pm 1.52$ & $174.3 \pm 1.32$ & $176.5 \pm 1.47$ & $182.1 \pm 1.83$ & $183.2 \pm 1.57$ \\
\hline
\end{tabular}

\subsection{Effect of crude extract and fractions of F.albida blood glucose level of normal and diabetic rats}

The blood glucose level of diabetic rats treated with F. albida extract $200 \mathrm{mg} / \mathrm{ml}$ (Table 3) was significantly lowered after 3 weeks of treatment compared to the untreated diabetic rats. The rats treated with ethyl acetate fraction $50 \mathrm{mg} / \mathrm{ml}$ and those treated with the control drug glibenclamide $5 \mathrm{mg} / \mathrm{ml}$ also led to significant decrease in the levels of blood glucose. The blood glucose level of the group treated with ethylacetate was lowered to $142 \mathrm{mg} / \mathrm{dl}$ which compares favourably with the group treated with glibenclamide $(112 \mathrm{mg} / \mathrm{dl})$ as opposed to the diabetic untreated group $(380 \mathrm{mg} / \mathrm{dl})$ at the end of four weeks of treatment. This result agrees with previous work on the effect of aqueous stem bark extract of F. albida. (Umar et al. 2014).

Table 3. Effect of crude extract of $F$. albida and fractions on blood glucose level in normal and diabetic rats

\begin{tabular}{|l|l|l|l|l|l|l|}
\hline GRP & & & WEEK 1 & WEEK 2 & WEEK 3 & WEEK 4 \\
\hline 1 & CRUDE EXTRACT FA & $\geq 450$ & $\geq 450$ & $287.3 \pm 2.55$ & $260.4 \pm 1.82$ & $250.4 \pm 1.15$ \\
\hline 2 & ETOAC FRACTION & $\geq 450$ & $429.2 \pm 2.11$ & $216.4 \pm 1.58$ & $183.6 \pm 2.11$ & $142.3 \pm 1.32$ \\
\hline 3 & BUTANOL FRACT & $\geq 450$ & $445.8 \pm 2.21$ & $419.1 \pm 1.07$ & $350.3 \pm 1.43$ & $280.5 \pm 1.62$ \\
\hline 4 & GLIBENCLAMIDE & $\geq 450$ & $350.9 \pm 1.63$ & $199.2 \pm 1.82$ & $126.7 \pm 1.58$ & $112.2 \pm 0.76$ \\
\hline 5 & DIABETIC & $\geq 450$ & $\geq 450$ & $416.5 \pm 0.92$ & $339.2 \pm 2.21$ & $380.2 \pm 1.37$ \\
\hline 6 & N CONTROL & $80.5 \pm 1.15$ & $83.3 \pm 0.22$ & $80.2 \pm 0.75$ & $78.9 \pm 0.55$ & $80.6 \pm 0.45$ \\
\hline
\end{tabular}

\subsection{Effect of crude extract and fractions of F.albida on lipid profile of normal and diabetic rats}

The administration of F.albida crude extract and fractions showed a significant hypolipidemic effect when compared to untreated diabetic rats. The total cholesterol (TC), Triglycerides (TG) and low density lipoprotein 
(LDL) levels were increased in diabetic rats when compared to control and treated rats. The increased level of serum cholesterol, TC, LDL poses a risk for developing vascular complications. The glibenclamide treated group showed similar lipid profile with the F.albida treated groups. The result of this study agrees with previous work on F.albida stem bark extract on lipid lowering properties (Umar .et al.,2014).

Table 4. Effect of crude extract and fractions of $F$. albida on serum lipid profiles in normal and diabetic rats

\begin{tabular}{|l|l|l|l|l|}
\hline GROUP & TOT.CHOLESTEROL & HDL & LDL & TRIGLYCERIDES \\
\hline 1 CRUDE FA & 100 & 20 & 66 & 70 \\
\hline 2 ETOAC & 108 & 22 & 81 & 153 \\
\hline 3 BUTANOL & 103 & 21 & 63 & 98 \\
\hline 4 GLIBENCLAMIDE & 100 & 20 & 64 & 79 \\
\hline 5 DIABETIC & 140 & 28 & 67 & 192 \\
\hline 6 N. CONTROL & 100 & 20 & 64 & 80 \\
\hline
\end{tabular}

\subsection{Effect of crude extract and fractions of F.albida on serum biochemical parameters}

The result of the effect of F.albida and its fractions (Table 5) on serum biochemical parameters indicated increase blood urea, increased total and conjugated bilirubin, significantly elevated ALT, AST and ALP for untreated diabetic rats and varying degrees of elevation for treated rats which are significantly lower than the values for diabetic rats. ALT, AST and ALP were significantly elevated in untreated diabetic rats (Table 4), these may be due to the necrotizing effect of alloxan on the liver cells. Some studies indicated that the level of these enzymes may be due to the dose of the diabetogenic compound used to induce diabetes in the rats (Ragbetli., 2010). Rats treated with extract and fractions showed markedly reduced enzyme levels compared to untreated rats. Kidney functions as indicated by creatinine and urea were elevated in diabetic rats, these could be signs of renal dysfunction caused by untreated diabetes or effect of necrotizing agent on the kidney. These values were lowered by the administration of the extract of F.albida and its fractions in varying degrees. These results agree with the previous studies on effect of F.albida extract on hyperglycaemia and hyperlipidemia in rats.

Table 5. Effect of crude extract and fractions of $F$. albida on serum biochemical parameters in normal and diabetic rats

\begin{tabular}{|l|l|l|l|l|l|l|l|}
\hline GROUP & UREA & CREATININE & $\begin{array}{l}\text { TOTAL } \\
\text { BILIRUBIN }\end{array}$ & $\begin{array}{l}\text { CONJ. } \\
\text { BILIRUBIN }\end{array}$ & ALT & AST & $\begin{array}{l}\text { ALKALINE } \\
\text { PHOSPHATASE }\end{array}$ \\
\hline 1 CRUDE & 154 & 0.54 & 0.50 & 0.40 & 254 & 78 & 739 \\
\hline 2 ETOAC & 16 & 0.50 & 0.50 & 0.20 & 173 & 41 & 395 \\
\hline 3 BUTAN & 53 & 1.49 & 0.50 & 0.30 & 176 & 50 & 20 \\
\hline 4 GLIBEN & 70 & 0.50 & 0.50 & 0.30 & 138 & 56 & 970 \\
\hline 5 DIABET & 169 & 0.57 & 1.50 & 0.70 & 909 & 303 & 3510 \\
\hline 6 CONTR & 53 & 0.50 & 0.50 & 0.20 & 126 & 26 & 101 \\
\hline
\end{tabular}

3.6 Effect of crude extract and fractions of $F$. albida on blood electrolytes of normal and diabetic rats The results presented in Tabale 6 indicated that serum electrolytes were relatively undisturbed and ere within range. There is no significant difference in the values obtained for normal and diabetic rats for the crude extract and fractions.

Table 6: Effect of crude extract and fractions of F.Albida on blood electrolytes of normal and diabetic wistar rats

\begin{tabular}{|l|l|l|l|l|}
\hline GROUP & Na+ & K+ & HCO3- & CL- \\
\hline 1 CRUDE & 138 & 5.2 & 13 & 101 \\
\hline 2 ETOAC & 144 & 6.7 & 15 & 92 \\
\hline 3 BUTANOL & 146 & 7.7 & 14 & 102 \\
\hline 4 GLIBENCLAMIDE & 136 & 4.9 & 16 & 101 \\
\hline 5 DIABETIC & 139 & 5.5 & 17 & 100 \\
\hline 6 N. CONTROL & 139 & 4.8 & 13 & 100 \\
\hline
\end{tabular}

\section{Conclusion}

This study revealed that F.albida extract reduce blood glucose level and improves weight gain in treated diabetic rats comparable to glibenclamide. It also demonstrate that there is an improved activity in the fractions especially ethylacetate fraction. This is an indication that compound(s) responsible for the observed antidiabetic action may be in the ethylacetate fraction and therefore considered as a candidate for bioassay guided fractionation for possible bioactive compound(s)

\section{Acknowledgement}

This work was funded by Tertiary Education fund grant of the Federal Government of Nigeria with support from African centre of excellence in Phytomedicine Research and Development , University of Jos, Nigeria 


\section{References}

[1] Abdalla M, Abdelatif, Mariam Y, Ibhrahim, Mahmoud S. Antidiabetic Effects of Fenugreek

[2] (Trigonella foenum - graecum) Seeds in the Domestic Rabbit (Oryctolagus cuniculus). Res J of

[3] Medicinal Plant 2012; 6: 449-455

[4] Brownlee M, Cerami A. The biochemistry of the complications of diabetes mellitus. Annual review of biochemistry 1981; 50 (1): $385-432$

[5] Doughari JH, Ndakidemi PA, Human IS, Benade S. Antioxidant, antimicrobial and antiverotoxic potentials of extracts of Curtisia dentata. J Ethnopharmacol2012;141: 1041-1050.

[6] Gaber KE, Singhal U, Daowd O, 2013. Hypoglycaemic and hypolipidaemic effects of some common plants extract in type 2 diabetic patients at Eldabba area ( North Sudan). IOSR J. Pharmac. Biol. Sci., 8:38-43.

[7] Inouyea S, Takizawab T, Yamaguchia H. Antibacterial activity of essential oils and their major constituents against respiratory tract pathogens by gaseous contact.J Antimicrob Chemother2001;47: 565-573

[8] Lawal AR., Agunu A., Ibrahim H and Ibrahim K, 2012. Acute toxicity and pharmacognostic studies of the root bark of Acacia albida Del. (Fabaceae). Niger. J. Pharm. Sci., 11:31-38

[9] Moller N. and Nair KS, 2008. Diabetes and protein metabolism. J. Am. Diabetes Assoc. 57:3-4

[10] Oluwakanyisola SSA, Adeniyi TY, Akingbasote JA and Florence OE, 2010. Acute and subacute toxicity study of ethanolic extract of the stem bark of Faidherbia albida (Del.) A. chev. (Mimosoidae) in rats. Afr. J. Biotechnol. 9:1218-1224.

[11] Ordonez AAL, Gomez JG, Vattuone MA and Isla MI., 2006: Antioxidant activities Sechium edule (Jacq.) Swart extracts. Food Chem. 97:452-458

[12] Pieroni A, Janiak V, Durr CM, Ludeke S, Trachsel E, Heinrich M. 2002: In vitro antioxidant activity of non-cultivated vegetables of ethnic Albanians in southern Italy. Phytother Res. 16 (5):467-473

[13] Ragbetli C. Ceylan E. Effect of Streptozotocin on Biochemical Parameters in Rats. Asian Journal of Chemistry 2010; 22(3): 2375

[14] Roby MHH, Sarham MA, Selim KAH and Khalil KI., 2013. Evaluation of antioxidant activity , total phenols and phenolic compounds in thyme ( Thymus vulgaris L.), sage ( Salvia officinalis L. ) and marjoram ( Origanum majorana L.) extracts. Ind. Crops Prod. 43: 827-831

[15] Salawu OA., Tijani AY., Babayi H., Anagbogu RA and Agbakwuru VA. 2010. Anti-malarial activity of ethanolic stem bark extract of Faidherbia albida (Del.) a. Chev (Mimosaceae) in mice. Arch. Applied Sci. Res. , 2:261-268

[16] Salisu Y. ,Agunu A., Abubakar MS, Ibrahim G., 2009. Hypoglycaemic effects of Acacia albida Del. (Mimosaceae) methanol root bark extract. Niger. J. Pharm. Sci., 8: 66-72.

[17] Sofowora A., 1993. Medicinal plants and traditional medicine in Africa. $2^{\text {nd }}$ Edition, Spectrum Book, Ibadan, Nigeria. 120-125

[18] Tijani AY., Uguru MO. and Salawu OA., 2008. Anti-pyretic , anti- inflammatory and anti- diarrhoeal properties of Faidherbia albida in rats. Afr. J. Biotechnol., 7: 696-700.

[19] Trease, GE, Evans WC 2002. Textbook of pharmacognosy. $14^{\text {th }}$ Edition. W.B. Saunders Company Ltd. 24-24 Oval Road, London NW1 7DX, UK and Printed by Harcourt Brace \& Company. 61-62

[20] Umar IA, Mohammed A, Ndidi US, Abdulazeez AB, Olisa WC, Adam M. 2014. Anti-Hyperglycemic and anti- Hyperlipidemic effects of aqueous stem bark extract of Acacia albida Delile. In alloxan induced diabetic rats. Asian J. Biochem. 9 (4): 170-178

[21] Usman WA., Mahmoud SJ. and Ahmed ZH., 2013. Antimicrobial activity of stem bark of Faidherbia albida. Br. J. Pharmaceut. Res., 3: 786-794.

[22] Vishwakarma SL, Rakesh S, Rajani M, Goyal RK. Evaluation of effect of aqueous extract of

[23] Enicostem malittorale Blume. In streptozotocin induced type 1 diabetic rats. Indian J ExpBiol 2010;48: 26-30.

[24] Wood PJ., 1992. The botany and distribution of Faidherbia albida. Proceedings of the workshop on Faidherbia albida in the West African Semi- Arid Tropics, April 22-26, 1991, Niamey, Niger . pp 9-17

\footnotetext{
A.J.Kashimawo. "Anti diabetic activity of the stem bark extract and fractions of Faidherbia albida Del. (Mimosaceae) in murine model." IOSR Journal of Pharmacy and Biological Sciences (IOSR-JPBS) 12.4 (2017): 26-30.
} 